$\prod$ огранично-лепроматозная Аепра с первичной кАинической манифестацией у пациента с Алительным дерматологическим анамнезом

(с) Янчевская Е.Ю. ${ }^{1}$, Ковтунова В.А. ${ }^{*}$, Думченко Е.В. ${ }^{2}$, Дуйко В.В. ${ }^{3}$, Левичева Ю.Ю. ${ }^{3}$

\author{
1 Федеральное государственное бюджетное образовательное учреждение высшего образования «Астраханский государ- \\ ственный медицинский университет» Министерства здравоохранения Российской Федерации \\ 414024, Россия, г. Астрахань, ул. Бакинская, д. 121 \\ ${ }^{2}$ Государственное бюджетное учреждение здравоохранения «Астраханский областной кожно-венерологический диспансер» \\ 414056, Россия, г. Астрахань, ул. М. Максаковой, д. 6 \\ ${ }^{3}$ Федеральное государственное бюджетное учреждение «Научно-исследовательский институт по изучению лепры» \\ Министерства здравоохранения Российской Федерации
}

414057, Россия, г. Астрахань, проезд Н. Островского, д. 3

Несмотря на достаточно низкие показатели заболеваемости лепрой, случаи заболевания ею продолжают регулярно выявляться, с преимущественной частотой регистрации на эндемичных территориях. В Российской Федерации одной из эндемичных территорий является Астраханская область. Длительный инкубационный период приводит к невозможности выявления источника инфицирования в ряде случаев. Сочетание лепрозного процесса с другими дерматозами затрудняет его диагностику. Единичные и ранние кожные проявления лепры ошибочно могут быть приняты за клинические признаки других дерматозов. В данной статье приводится описание клинического наблюдения погранично-лепроматозной лепры у пациента с длительным дерматологическим анамнезом. Пациент 66 лет на протяжении 14 лет наблюдался с различными дерматологическими заболеваниями. В 2017 г. после изменения характера высыпаний, нетипичных для курируемых нозологических фрорм, и в связи с резистентностью клинических проявлений заболевания к проведенной терапии был установлен клинический диагноз лепры. Для верификации этого диагноза пациент был направлен в Федеральное государственное бюджетное учреждение «Научно-исследовательский институт по изучению лепры». При поступлении предъявлял жалобы на высыпания на коже лица, туловища, конечностей, сопровождающиеся зудом, отечностью, слабость и онемение в дистальных отделах конечностей. В результате клинического, лабораторного обследования (бактериоскопического исследования скарификатов с кожи, серологического исследования, патоморфологического исследования биоптатов кожи) был выставлен диагноз основного заболевания: лепра, погранично-лепроматозная форма, активная стадия; осложнения основного заболевания: хроническая специфическая полинейропатия с чувствительными нарушениями. Описанная клиническая ситуация иллюстрирует проблему ранней диагностики лепры из-за многообразия проявлений и низкой настороженности клиницистов.

Ключевые слова: лепра, Мусоbcterium leprae, дифференциальная диагностика, сочетанное заболевание, клинический случай.

Конфлликт интересов: авторы заявляют об отсутствии потенциального конфликта интересов, требующего раскрытия в данной статье.

Источник фринансирования: клиническое наблюдение было проведено в Государственном бюджетном учреждении здравоохранения «Астраханский областной кожно-венерологический диспансер» и клиническом отделении Федерального Государственного бюджетного учреждения «Научно-исследовательский институт по изучению лепры» Министерства здравоохранения Российской Федерации.

Согласие пациента: пациент добровольно подписал информированное согласие на публикацию персональной медицинской информации в обезличенной фрорме в журнале «Вестник дерматологии и венерологии».

Для цитирования: Янчевская Е.Ю., Ковтунова В.А., Думченко Е.В., Дуйко В.В., Левичева Ю.Ю. Пограничнолепроматозная лепра с первичной клинической манифестацией у пациента с длительным дерматологическим анамнезом. Вестник дерматологии и венерологии. 2020;96(5):53-58.

doi: https://doi.org/10.25208/vdv1166-2020-96-5-53-58 


\title{
Borderline lepromatous leprosy with primary clinical manifestation in a patient with a long-term dermatological history
}

\author{
(c) Elena Yu. Yanchevskaya ${ }^{1}$, Violetta A. Kovtunova ${ }^{1 *}$, Egor V. Dumchenko², Victor V. Duiko ${ }^{3}$, Yulia Yu. Levicheva ${ }^{3}$
}

\author{
${ }^{1}$ Astrakhan State Medical University \\ Bakinskaya str., 121, Astrakhan, 414024, Russia \\ ${ }^{2}$ Regional Center of Skin and Sexually Transmitted Diseases \\ M. Maksakova str., 6, Astrakhan, 414056, Russia \\ ${ }^{3}$ Leprosy Research Institute \\ N. Ostrovsky str., 3, Astrakhan, 414057, Russia
}

Despite the low number, the cases of leprosy continue to be detected, more often on endemic territories. In Russian Federation one of the endemic territories is located in Astrakhan region. The long incubation period eventually leads to inability to identify the source of infection. The combination of the leprosy with other dermatoses complicates the diagnosing. The isolated and early skin manifestations of leprosy can be mistaken for the clinical features of other dermatoses. This article presents the description of a case study of border line lepromatosis leprosy in a patient with a long-term dermatological background. A 66-year-old male was followed up for 14 years under different dermatological diseases. In 2017, after a change in the nature of rashes, atypical for supervised nosological forms, and in connection with the resistance of clinical manifestations of diseases to the therapy, a clinical diagnosis of leprosy was established. To verify this diagnosis, the patient was sent to the Federal State Budgetary Institution "Research Institute for the Study of Leprosy". At admission, he complained of rashes on the skin of the face, trunk, extremities, accompanied by itching, swelling, weakness and numbness in the distal extremities. As a result of clinical, laboratory examination (bacterioscopic examination of scarification from the skin, serological examination, pathomorphological examination of skin biopsies), the diagnosis of the underlying disease was made: leprosy, borderline lepromatous form, active stage. Complications of the underlying disease: chronic specific polyneuropathy with sensitive disorders. The described clinical situation illustrates the problem of early diagnosis of leprosy due to the variety of manifestations and low alertness of clinicians.

\section{Keywords: leprosy, Mycobacterium leprae, differential diagnosis, comorbidities, case report.}

Conflict of interest: the authors state that there is no potential conflict of interest requiring disclosure in this article.

Source of funding: the clinical observation was conducted at the Astrakhan Oblast Dermatovenerologic Dispensary and the clinical unit of the Federal State Budgetary Institution "Research Institute for the Study of Leprosy" of the Ministry of Health of the Russian Federation.

Patient's consent: the Patient signed a voluntary consent to publish personal health information in anonymized form in the journal "Vestnik Dermatologii I Venerologii".

For citation: Yanchevskaya E.Yu., Kovtunova V.A., Dumchenko E.V., Duiko V.V., Levicheva Yu.Yu. Borderline lepromatous leprosy with primary clinical manifestation in a patient with a long-term dermatological history. Vestnik Dermatologii i Venerologii. 2020;96(5):53-58. doi: https://doi.org/10.25208/vdv1166-2020-96-5-53-58 
Лепра - хроническое гранулематозное инфекционное заболевание, вызываемое Mycobacterium leprae, имеющее длительный инкубационный период. Представляя собой инфекционное заболевание общемирового значения, лепра встречается преимущественно на эндемичных территориях. Наибольшая частота регистрации лепры отмечается в тропических регионах, до $80 \%$ - в Юго-Восточной Азии и Бразилии. В Российской Федерации одним из эндемичных регионов является Астраханская область. Высокая интенсивность миграции по всему миру приводит к появлению завозных случаев лепры в странах Евросоюза, в Российской Федерации [1-3].

Длительный (до 20 лет) инкубационный период не всегда позволяет установить источник заражения. Лепра поражает в первую очередь периферические нервы, кожу и слизистые верхних отделов дыхательного тракта. В клинической практике в течение длительного времени использовалась классификация лепрозного процесса Ридли - Джоплинга (1973 г.), дополнившая ранее существовавшую мадридскую классификацию, включающая в себя недифференцированный, полярный туберкулоидный, субполярный туберкулоидный, погранично-туберкулоидный, пограничный, погранично-лепроматозный, субполярный лепроматозный, полярный лепроматозный типы. В современной классифрикации Всемирной организации здравоохранения (ВОЗ) лепра подразделяется на малобактериальную и многобактериальную фрормы [4].

На сегодняшний день ВОЗ выделяет три основных признака лепры: снижение чувствительности в местах кожных высыпаний, утолщение периферических нервов, позитивные лабораторные тесты (скарификаты). Согласно рекомендациям ВОЗ, диагноз лепры устанавливается при наличии двух положительных признаков. Гистологическое исследование биоптата, при его правильном взятии, делает диагностику лепры в ряде случаев более успешной [1]. Так, при лепроматозном типе лепры рекомендовано осуществлять взятие материала с периферии высыпаний, а при туберкулоидном типе - с центральной части элементов [1, 4]. В связи с вариабельной клиникой лепра требует дифференциальной диагностики с другими воспалительными заболеваниями [5].

\section{Описание случая}

В данной статье мы приводим описание клинического наблюдения погранично-лепроматозной лепры, манифестировавшей первично у пациента с длительным дерматологическим анамнезом.

Пациент Б., 1951 г. р., проживает в Харабалинском районе Астраханской области. С детства до 1985 г. часто менял место жительства: Ставропольский край, Республика Калмыкия, Енотаевский район Астраханской области. Работал трактористом, к моменту госпитализации вышел на пенсию. Женат, имеет детей. Наличие больных лепрой среди членов семьи, родственников или соседей отрицает. Анамнез отягощен туберкулезом с оперативным удалением туберкуломы легких в 1992 г.

Наличие кожных высыпаний отмечает в течение 14 лет. На протяжении этого времени наблюдался в Государственном бюджетном учреждении здравоохранения «Астраханский областной кожно-венерологический диспансер» (ГБУЗ АО ОКВД) с различными диагноза- ми: токсикодермия, аллергический дерматит, почесуха, экзема лица, нейродермит распространенный. Больной предъявлял жалобы на зуд, чувство стягивания кожи. Наблюдались эритема и инфильтрация в области лица, туловища, конечностей, белый дермографизм.

С осени 2017 г. отметил изменение характера и локализации высыпаний: появилась отечность лица, ушных раковин. После проведенной системной терапии преднизолоном в дозе 60 мг в/в 7 дней и 20 мг перорально 15 дней было отмечено незначительное клиническое улучшение в виде побледнения элементов и уменьшения их инфильтрации, однако полного регресса сыпи не наблюдалось.

В связи с резистентностью клинических проявлений заболевания к проведенной терапии и формированием на ее фоне нетипичных для курируемых нозологических форм высыпаний в декабре 2017 г. был установлен клинический диагноз лепры. Для верификации этого диагноза пациент был направлен в Федеральное государственное бюджетное учреждение «Научно-исследовательский институт по изучению лепры» (ФГБУ «НИИЛ» Минздрава России). При поступлении предъявлял жалобы на высыпания на коже лица, туловища, конечностей, сопровождающиеся зудом, отечностью, слабость и онемение в дистальных отделах конечностей. На момент поступления в ФГБУ «НИИЛ» Минздрава России состояние больного расценивалось как среднетяжелое вследствие активного течения лепрозного процесса и сопутствующей патологии.

\section{Результаты физикального, лабораторного и инструментального исследований}

Высыпания на коже носили распространенный характер. В области лба, носа, щек, подбородка, шеи отмечалась эритема ярко-красного цвета, инфильтрация (рис. 1). Преимущественная выраженность инфильтрации наблюдалась в области надбровных дуг, носа,

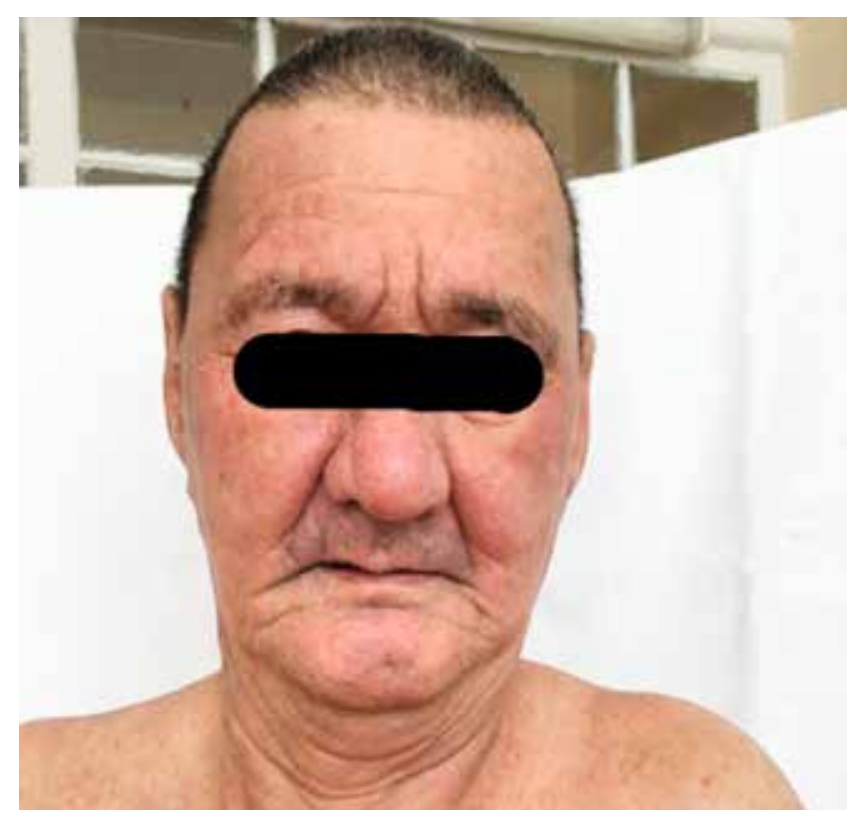

Рис. 1. Эритема и инсиильтрация в области лица Fig. 1. The erythema and the infiltration in the face 
подбородка. На ее фроне в области лба, переносицы располагались очень глубокие складки кожи. Отмечалась выраженная разреженность бровей с наибольшим преобладанием в их латеральной части. Ушные раковины были инфильтрированы, увеличены в размере (рис. 2). На коже правой половины грудной клетки располагалось пятно с четкими границами застойно-красного цвета размером 2,5 на 5,0 см (рис. 3). На коже спины наблюдались множественные депигментированные пятна. Кожа туловища, верхних и нижних конечностей была сухая, местами с шелушением. В области кистей и стоп отмечался акроцианоз. В области предплечий, голеней - выпадение пушковых волос. На отдельных участках кожного покрова имелись вазомоторные нарушения в виде мраморности кожи.

На осмотре у невролога пациент эмоционально лабилен, возбудим. Память ослаблена. Функция мимических мышц нарушена слева. Наблюдалось снижение силы мышц в левой кисти. Понижены все виды чувствительности в области верхних и нижних конечностей, больше справа. Выявлен патологический рефлекс Маринеску - Радовича. Отмечалась атрофрия дельтовидных мышц, лопаточных мышц, контрактуры Дюпюитрена.

Выявлена положительная никотиновая проба. После внутривенного медленного струйного введения 6,0 мл 1\%-го раствора никотиновой кислоты на 5-й минуте появились эритема и отечность в области кожи лица, ушных раковин. На 7-й минуте эритема распространилась на кожу верхних и нижних конечностей, туловища. На 20-й минуте от момента введения сохранялись отдельные пятна красного с цианотичным оттенком на коже правой половины грудной клетки, верхней трети внутренней поверхности правого предплечья, запястья, в области наружной поверхности бедер. Феномен «отека и воспаления» - положительный.

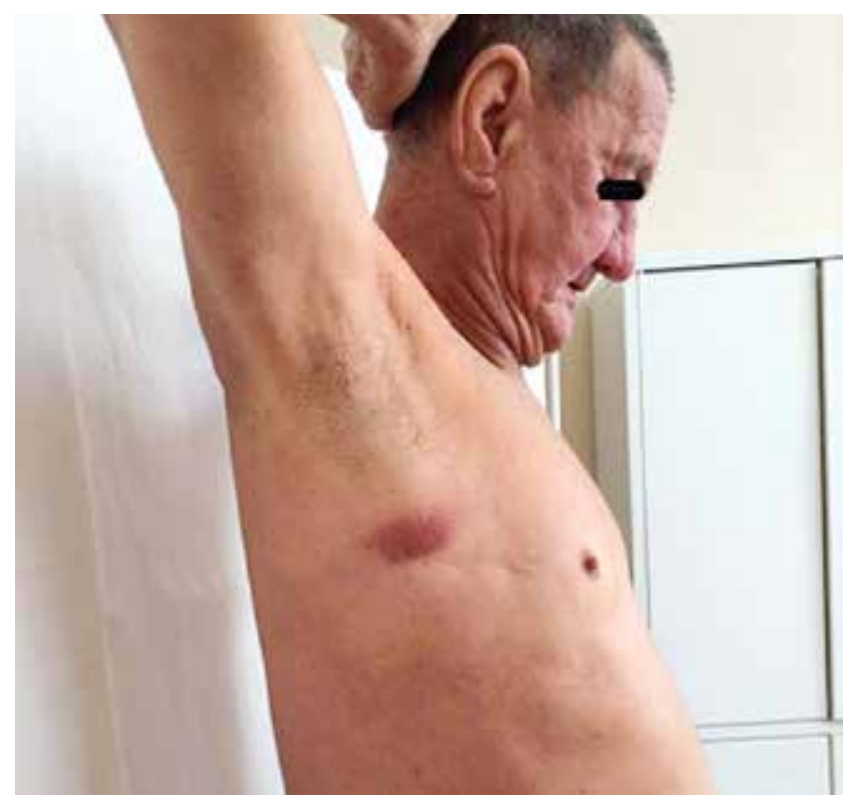

Рис. 2. Инсилльтрация ушных раковин и разреженность роста бровей в латеральной части

Fig. 2. The infiltration of the ears and the sparse growth of the eyebrows in the lateral part
При гистологическом исследовании биоптата кожи с пятна на правой половине грудной клетки: эпидермис с гиперкератозом и умеренно выраженным акантозом, в сосочковом слое дермы лимфрогистиоцитарная инфильтрация, в инфильтрате большое количество клеток с вакуолизированной цитоплазмой, встречались единичные эозинофилы и нейтрофилы; капилляры дермы с расширенными просветами. При окраске по Циль Нильсену были обнаружены микобактерии, располагавшиеся внутри и внеклеточно.

При бактериоскопическом исследовании скарификатов с кожи мочки левого уха были обнаружены кислотоустойчивые микобактерии: гомогенные M. leprae 64 , зернистые M. leprae - 22, зерна M. leprae - 50 .

Серологический анализ крови: уровень антител к DIS-BSA IgG - 0,29 (норма 0,20); уровень антител к DIS-BSA IgM - 0,25 (норма 0,15); циркулирующие иммунные комплексы - 16,3.

В общем анализе крови: эритроциты 5,39 на 1012, цветной показатель - 0,8, лейкоциты - 12,05 на $10^{9}$. В биохимическом анализе крови 05.12.2017: общий белок 63,4 г/л, гамма-глутамилтрансфераза - 37,2 ед/л.

На основании клинической картины и результатов лабораторных исследований был выставлен диагноз основного заболевания: лепра, погранично-лепроматозная форма, активная стадия; осложнения основного заболевания: хроническая специфическая полинейропатия с чувствительными нарушениями.

\section{Лечение}

Специфическая терапия проводилась с момента установления диагноза лепры и продолжается по настоящее время в соответствии со «Стандартом специализированной медицинской помощи при лепре, активная стадия» (от 22.03.2013): дапсон 100 мг ежедневно, рифампицин 600 мг 1 раз в месяц. С целью снижения

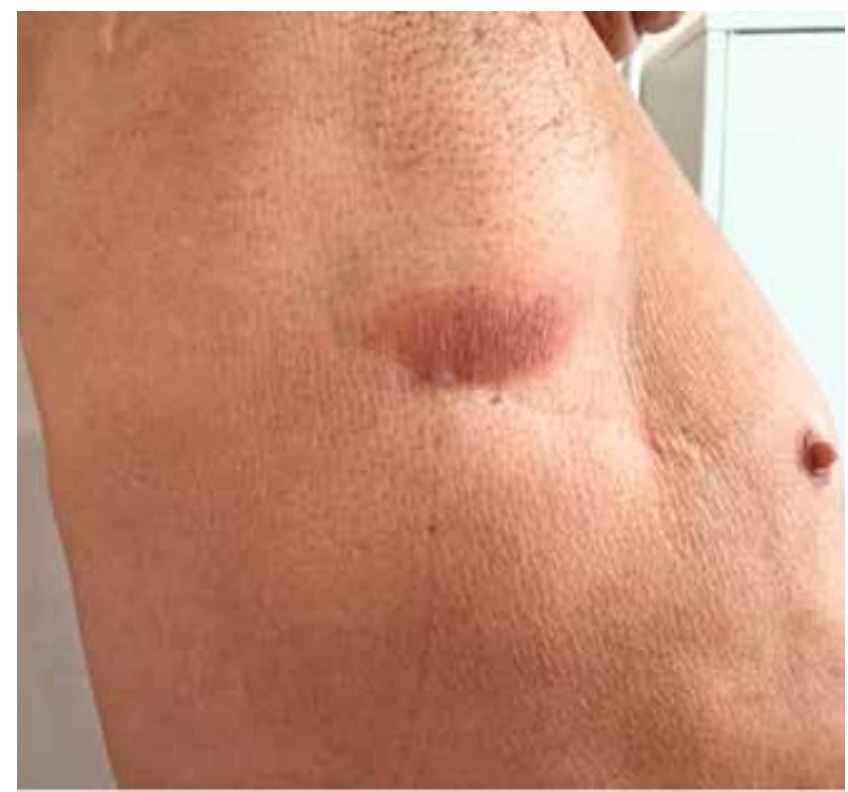

Рис. 3. Пятно застойно-красного цвета в области правой половины грудной клетки Fig. 3. The deep red macule in the right side of the thorax 
побочных эфрфектов противолепрозной терапии в виде нейро- и гепатотоксичности применялись нейропротекторы (тиоктовая кислота, витамины группы В) и гепатопротекторы (гептрал, эссенциале фрорте). Проводилось курсовое фризиотерапевтическое лечение (магнитои лазеротерапия, фонофрорез с раствором тиоктовой кислоты).

В результате проводимой терапии эритема и инфрильтрация разрешились, пятно в области правой половины грудной клетки побледнело, приобрело розовато-коричневый цвет, уменьшилось в размерах. С июня 2020 г. у больного бактериовыделение прекратилось.

\section{Обсуждение}

Данное клиническое наблюдение свидетельствует о возможной сложности в установлении правильного клинического диагноза у пациента с сочетанием длительно протекающего неспецифического поражения кожи и специфического лепрозного процесса. Появление новой клинической симптоматики должно насторожить врача по поводу возможного присоединения другого заболевания. Атипичное течение лепры может увести клинициста от правильного диагноза, особенно если в анамнезе отсутствуют данные о контакте с больными лепрой. Описанный в нашей статье клинический случай нельзя рассматривать как диагностическую ошибку и атипичный вариант течения лепры. В данном случае следует думать о длительном хроническом неспецифическом дерматозе, на фроне которого клинически манифрестировала лепра. Подтверждением этого являются жалобы больного на длительный интенсивный зуд кожи, нетипичные для лепры высыпания и особенности патоморфологической картины биоптата кожи.

Выявленные при гистологическом исследовании кожного биоптата акантоз и гиперкератоз могут встречаться при нейродермите (L 20.8), хронической экземе, хронических фрормах почесухи. Для лепроматозной лепры характерным является уплощенный и атрофичный эпидермис.

Присутствующая в сосочковом слое дермы лимфогистиоцитарная инфильтрация с примесью других клеток и расширение капилляров являются признаками, которые могут встречаться как при многих неинфекционных дерматозах, так и при лепре. Между тем для лепрозного процесса не являются характерными обнаруженные в кожном биоптате пациента клетки с вакуолизированной цитоплазмой. Этот признак более типичен для хронической экземы [6]. Таким образом, только внутри и внеклеточно расположенные микобактерии, обнаруженные при окрашивании препарата по Циль - Нильсену, явились специфичными признаками для гистологической картины лепры.

С другой стороны, общее улучшение кожного статуса пациента можно рассматривать не только как положительный ответ на специфическую противолепрозную терапию, но и как следствие эффективности назначения дапсона при хронических неспецифических дерматозах.

\section{Заключение}

Сочетание кожного лепрозного процесса с другими дерматозами может приводить к дополнительным трудностям в диагностике. Вариабельность клинических проявлений лепры требует дифференцирования eе с различными дерматозами, в том числе негранулематозными [5]. Знание ранних и единичных проявлений лепры является важным в клинической практике, способствует своевременному установлению диагноза, раннему началу специфической терапии и предупреждению поздних осложнений. Формирование настороженности относительно заболевания лепрой важно не только среди дерматовенерологов, но и врачей смежных специальностей.

\section{Литература/References}

1. Alemi Belachew W, Naafs B. Position statement: LEPROSY: Diagnosis, treatment and follow-up. Journal of the European Academy of Dermatolology and Venereology. 2019;33(7):1205-1213.

2. De Souza CDC, Rocha VC, Santos NF, Leal TC, De Paiva JPS, Oliveira CCC, Martins-Filho PRS, Magalhaes MAFM, Cuevas LE, Santos VS. Spatial clustering, social vulnerability and risk of leprosy in an endemic area in Northeast Brazil: an ecological study. Journal of the European Academy of Dermatology and Venereology. 2019;33(8):1581-1590.

3. Янчевская Е.Ю., Меснянкина О.А. Лепра: современные представления о путях передачи. Кубанский медицинский вестник. 2019;26(4):123-130. [Yanchevskaya EYu, Mesnyankina OA. Leprosy: modern views on the modes of its transmission. Kubanskii Nauchnyi Meditsinskii Vestnik. 2019;6(4):123-130 (In Russ.)]
4. World Health Organization. Guidelines for the diagnosis, treatment and prevention of leprosy, 2018. http://www.searo.who.int/entity/global_leprosy_programme/documents/9789290226383/en/

5. Семенова В.Г., Карамова А.Э., Нефедова М.А. Лепра под «маской» туберкулеза кожи - трудности диагностики. Вестник дерматологии и венерологии. 2017;93(6):91-99. [Semyonova VG, Karamova AE, Nefyodova MA. Leprosy in the guise of skin tuberculosis - complexities of diagnostics. Vestnik Dermatologii i Venerologii. 2017;93(6):91-96 (In Russ.)]

6. Цветкова Г.М., Мордовцева В.В., Вавилов А.М., Мордовцев В.Н. Патоморфология болезней кожи. Москва: Медицина. 2003. 496 с. [Tsvetkova GM, Mordovtseva VV, Vavilov AM, Mordovtsev VN. Pathomorphology of skin diseases. Moscow: Meditsina. 2003. 496 p. (In Russ.)] 


\section{Информация об авторах}

Елена Юрьевна Янчевская - К.м.Н., доцент, и. о. заведующего кафедрой дерматовенерологии Астраханского государственного медицинского университета Министерства здравоохранения Российской Федерации; тел.: +7 (908) 616-38-79; ORCID ID: 0000-0002-3741-4528; eLibrary SPIN: 8004-3847; e-mail: apteca-111a@mail.ru

Виолетта Анатольевна Ковтунова - К.м.Н., доцент, доцент кафедры дерматовенерологии Астраханского государственного медицинского университета Министерства здравоохранения Российской Федерации; тел.: +7 (908) 616-26-44; ORCID ID: 0000-0002-8486-7095; eLibrary SPIN: 5399-1688; e-mail: violetta_kovtunova@mail.ru

Егор Вадимович Думченко - врач-дерматовенеролог Астраханского областного кожно-венерологического диспансера; тел.: +7 (967) 829-70-77; ORCID ID: 0000-0002-4992-6010; e-mail: 89678297077@mail.ru

Виктор Васильевич Дуйко - д.м.Н., директор Научно-исследовательского института по изучению лепры Министерства здравоохранения Российской Федерации; тел.: +7 (8512) 33-96-33, тел.: +7 (917) 087-76-67; ORCID ID: 0000-0002-0606-7316; eLibrary SPIN: 3706-4101; e-mail: V.Duiko@yandex.ru

Юлия Юрьевна Левичева - заведующая клиническим отделением Научно-исследовательского института по изучению лепры Министерства здравоохранения Российской Федерации; раб. тел.: +7 (8512) 33-39-33, тел.: +7 (917) 171-10-11; ORCID ID: 0000-0002-1962-4193; eLibrary SPIN: 5659-9959; e-mail: levicheva@700200.ru

\section{Information about the authors}

Elena Yu. Yanchevskaya - Cand. Sci. (Med.), Assoc. Prof., Head of Department of Dermatovenerology, Astrakhan State Medical University, Ministry of Health of the Russian Federation; tel.: +7 (908) 616-38-79; ORCID ID: 0000-0002-3741-4528; eLibrary SPIN: 8004-3847; e-mail: apteca111a@mail.ru

Violetta A. Kovtunova - Cand. Sci. (Med.), Assoc. Prof., Department of Dermatovenerology, Astrakhan State Medical University, Ministry of Health of the Russian Federation; tel.: +7 (908) 616-26-44; ORCID ID: 0000-0002-8486-7095; eLibrary SPIN: 5399-1688; e-mail: violetta_kovtunova@mail.ru

Egor V. Dumchenko - Dermatovenerologist, Regional Center of Skin and Sexually Transmitted Diseases; tel.: +7 (967) 829-70-77; 0RCID ID: 0000-0002-4992-6010; e-mail: 89678297077@mail.ru

Victor V. Duiko - Dr. Sci. (Med.), Director, Leprosy Research Institute, Ministry of Health of the Russian Federation; tel.: +7 (8512) 33-96-33, tel.: +7 (917) 087-76-67; ORCID ID: 0000-0002-0606-7316; eLibrary SPIN: 3706-4101; e-mail: V.Duiko@yandex.ru

Yulia Yu. Levicheva - Head of Clinical Department, Leprosy Research Institute, Ministry of Health of the Russian Federation; tel.: +7 (8512) 33-39-33, tel.: +7 (917) 171-10-11; ORCID ID: 0000-0002-1962-4193; eLibrary SPIN: 5659-9959; e-mail: levicheva@700200.ru

Статья поступила в редакцию: 01.09.2020

Принята к публикации: 30.10 .2020

Дата публикации: 02.12.2020
Submitted: 01.09.2020

Accepted: 30.10 .2020

Published: 02.12 .2020 